\title{
Influence of Buffer Agent Concentration on the Optical Properties from CdS Nanocrystals on Silicon Nanoporous Pillar Array
}

\author{
Peng Fei Ji, ${ }^{1}$ Wei Fen Jiang, ${ }^{2}$ Yong Li, ${ }^{1}$ Yue Li Song, ${ }^{1}$ Ming Li Wan, ${ }^{1}$ and Feng Qun Zhou \\ ${ }^{1}$ Department of Physics and Solar Energy Research Center, Pingdingshan University, Pingdingshan 467000, China \\ ${ }^{2}$ Department of Mathematics and Information Science, North China University of Water Resources and Electric Power, \\ Zhengzhou 450045, China
}

Correspondence should be addressed to Yong Li; liyong@pdsu.edu.cn

Received 4 May 2015; Revised 11 September 2015; Accepted 7 October 2015

Academic Editor: Paresh Chandra Ray

Copyright @ 2015 Peng Fei Ji et al. This is an open access article distributed under the Creative Commons Attribution License, which permits unrestricted use, distribution, and reproduction in any medium, provided the original work is properly cited.

\begin{abstract}
The chemical bath deposition (CBD) method is very crucial to the reaction rate. Generally, the rate can be controlled through tuning buffer agent concentration. CdS nanocrystals on the silicon nanoporous pillar array (CdS/Si-NPA) have been prepared through the $\mathrm{CBD}$ method. By varying the buffer agent concentration, the reaction rates can be tuned. The diffraction peaks of hexagonal CdS and $\mathrm{Cd}$ can be observed due to the reduction of $\mathrm{Cd}^{2+}$ caused by the silicon nanoporous pillar array. The average size of CdS nanocrystals is decreased with the increasing buffer agent concentration and the optical band gaps from CdS nanocrystals are increased. From the photoluminescence of CdS/Si-NPA, it can be observed that the blue emissions are independent of the buffer agent concentration and the green emissions show blue shift with the increasing buffer agent concentration.
\end{abstract}

\section{Introduction}

Nanocrystal semiconductors have been a subject of more attention due to their important physical and chemical properties compared to the bulks. Current research on nanocrystals is focused on the fabrication method, the origins of photoluminescence, and the tune of band gaps $[1,2]$. According to the quantum size effect, the band gap is dependent on the size of nanocrystals below certain size [3, 4]. Through varying the growth condition and environment, the size of nanocrystals can be controlled and then the optical properties can be tuned.

$\mathrm{CdS}$ is an important semiconductor with a direct band gap of $\sim 2.40 \mathrm{eV}$ at room temperature, which can be fabricated through the solvothermal, hydrothermal, and physi$\mathrm{cal} /$ chemical vapor deposition and chemical bath deposition (CBD) methods [5-9]. Based on high sensitivity and effect photophysical properties, CdS is suitable for the applications in the fields of photodetectors, light-emitting diodes, lasers, and solar cells [10-12]. In our previous works, we have synthesized CdS nanocrystals on the silicon nanoporous pillar array
(CdS/Si-NPA) by the CBD method. Based on CdS/Si-NPA, light-emitting diodes and photovoltaic devices have been investigated $[13,14]$. However, the low quantum efficiency and energy conversion efficiency can be observed. For these devices a detailed knowledge of the defects and band gap for CdS nanocrystals is essential. Generally photoluminescence (PL) experiments have been utilized to investigate the defects and band gap in the field of nanocrystals semiconductors.

In this paper, CdS/Si-NPA has been fabricated through the CBD method. To investigate the evolution of size and optical properties, the buffer agent with difference concentration, respectively, has been added to the reaction solution. With the increasing buffer agent concentration, $\mathrm{Cd}$ nanocrystals have been observed. The optical properties from $\mathrm{CdS} / \mathrm{Si}$-NPA with the increasing buffer agent concentration have been discussed in detail.

\section{Experiments}

Si-NPA was prepared by hydrothermally etching (111) oriented, p-type single crystal silicon ( $s c$-Si) wafers in the aqueous solution of hydrofluoric acid containing ferric nitrate, 
the procedure and conditions of which have been described in detail elsewhere [15]. The CdS thin film was deposited on Si-NPA by a CBD method and the preparing procedures were described as follows. The bath solution was prepared by mixing the solutions of cadmium chloride $\left(0.04 \mathrm{~mol} \mathrm{~L}^{-1}\right.$, $75 \mathrm{~mL})$ and aqueous ammonia $(25-28 \%, 15 \mathrm{~mL})$. The solution was kept at $80^{\circ} \mathrm{C}$ for 60 minutes under continuous magnetic agitation to homogenize the mixture. Subsequently, $5 \mathrm{~mL}$ thiourea $\left(2.0 \mathrm{~mol} \mathrm{~L}^{-1}\right)$ was added to the mixed solution. Five minutes later, Si-NPA substrate was immersed in the solution for $40 \mathrm{~min}$ to grow $\mathrm{CdS}$ thin films. Then the sample was taken out of the solution, washed with deionized water and ethanol in turn, and dried in the nitrogen flow.

In the above experiment process, after the thiourea was added to the solution the yellow flocculent precipitate can be seen by naked eyes. The faster reaction process introduced a large number of defects into the CdS nanocrystals [16] and decreased the physical properties of the devices based on these CdS nanocrystals [17]. To increase the quality of CdS nanocrystals, the reaction process must be slowed. In the chemical reaction process, ammonium chloride $\left(\mathrm{NH}_{4} \mathrm{Cl}\right)$ was used as a buffering agent to slow down the chemical reaction rate. So, we added $5 \mathrm{~mL} 0.05 \mathrm{~mol} / \mathrm{L}, 0.1 \mathrm{~mol} / \mathrm{L}$, and $0.15 \mathrm{~mol} / \mathrm{L}$ ammonium chloride to the solution before the thiourea was added, respectively. The other processes were the same as the above ones.

The morphology and structures of as-prepared CdS/SiNPA were characterized by a field-emission scanning electron microscope (FE-SEM, JSM 6700F) and a powder X-ray diffractometer (XRD, Panalytical $\mathrm{X}^{\prime}$ Pert Pro) using $\mathrm{CuK} \alpha$ as the $\mathrm{X}$-ray source $(\lambda=1.5046 \AA)$, respectively. The integral diffuse reflection spectra of CdS/Si-NPA were measured with UV-vis-IR spectrophotometer (Shimadzu, UV-3150) equipped with an integrating sphere. The room-temperature PL was measured using a double grating spectrofluorometer (HORIBA Jobin Yvon, FL3-22) with Xe lamp as an excitation source.

\section{Results and Discussions}

To investigate the structures of CdS/Si-NPA, the XRD spectra of the samples with the different concentration of buffer agent are shown in Figure 1, respectively. The spectra are normalized according to the intensity of the strongest diffraction peak self. As can be seen from Figure 1, the XRD spectrum of CdS/Si-NPA with no buffer agent shows three stronger peaks, which are located at $26.65^{\circ}, 44.16^{\circ}$, and $52.38^{\circ}$, that can be indexed to the reflections from the crystal family planes of hexagonal CdS (002), (110), and (112), respectively. To CdS/SiNPA with the buffer agent, however, two sets of diffraction peaks can be observed in each spectrum, which are indexed to the diffractions from hexagonal CdS and hexagonal Cd, respectively. Obviously, the peaks located at $31.72^{\circ}, 34.69^{\circ}$, and $38.39^{\circ}$ can correspond to the reflections from the crystal family planes of Cd (002), (100), and (101), respectively.

From Figure 1, it can be seen that the full width at half maximum (FWHM) of the (002) diffraction peaks for CdS nanocrystals is increased correspondingly with the increasing concentration of buffer agent. According to the principle of XRD, the increase of FWHM might reflect the decrease of the average size of nanocrystals [13]. Based on Scherrer's formula [6] and the data corresponding to the (002) diffraction peaks, the average sizes of CdS nanocrystals with the different concentration of buffer agent are calculated as $\sim 26.9 \mathrm{~nm}, \sim 19.2 \mathrm{~nm}, \sim 11.6 \mathrm{~nm}$, and $\sim 8.1 \mathrm{~nm}$, respectively. Obviously, the average size of CdS nanocrystals is decreasing with the increasing concentration of buffer agent. As for the diffraction from $\mathrm{Cd}$, it is easily found that its relative intensities gradually increase with the concentration of buffer agent. These can be explained from the increasing film thickness. As we know, CdS nanocrystals are located at the interface of nc-CdS and Si-NPA $[9,13,14]$. Then, the thicker $\mathrm{CdS}$ films impede the penetration of X-ray into nc-Cd and lead to the decrease of the diffraction peak intensity from $\mathrm{Cd}$ nanocrystallites.

The surface of Si-NPA usually exhibits strong chemical reducibility and can directly reduce metal ions from their solution [18]. The similar reduction process might also occur to form Cd nanocrystals, as follows: $\mathrm{Cd}^{2+}+\mathrm{e}^{-} \rightarrow \mathrm{Cd}$. With the increasing concentration of buffer agent, the reaction rate is more and more slower and the thickness of CdS films becomes more and more thinner at the same deposition time. So, the surface of Si-NPA will be insulated gradually from the cadmium ions in the solution and prevent further deposition or growing of $\mathrm{Cd}$. Therefore, the growing of $\mathrm{Cd}$ is a selflimited process which mainly occurs at the initial stage of the CBD process.

The morphologies of prepared CdS/Si-NPA with the different concentration of buffer agent are displayed in Figure 2. Obviously, the characteristic of the regular array of Si-NPA is maintained in CdS/Si-NPA [15], and both the pillars and the valleys are covered by the CdS films. From Figure 2(a), some flocculation and big size particles can be observed and pell-mell pilled on the pillars and between the pillars and valleys. From the analysis of XRD data, it is known that the average sizes of CdS nanocrystals are in the range of $8.0 \mathrm{~nm}$ and $30 \mathrm{~nm}$. Therefore, we think that the flocculation and big size particles should be the agglomerates of CdS nanocrystals. With increasing the buffer agent concentration, the flocculation is vanished and the size of the particles is decreasing. Under the buffer agent concentration of $0.10 \mathrm{~mol} \mathrm{~L}^{-1}$, the average size of particles is $\sim 190 \mathrm{~nm}$ [13]. However, with the concentration of $0.15 \mathrm{~mol} \mathrm{~L}^{-1}$ the average size of particles is estimated to be $\sim 110 \mathrm{~nm}$ and CdS thin films can be observed to be uniformly covered on the pillars and valleys.

The optical absorption of prepared CdS/Si-NPA with the different concentration for buffer agent is showed in Figure 3(a). As can be seen, with the increasing concentration the absorption is increasing. It is obvious that the absorption spectra have the gradual variation of absorption edge between $\sim 450 \mathrm{~nm}$ and $\sim 590 \mathrm{~nm}$, and the wider absorption bands indicate that the size distribution of CdS nanocrystals is much bigger. The value of optical band gap can be determined from the absorption using Tauc's relation [19]:

$$
(\alpha h v)^{n}=B\left(h \nu-E_{g}\right) .
$$




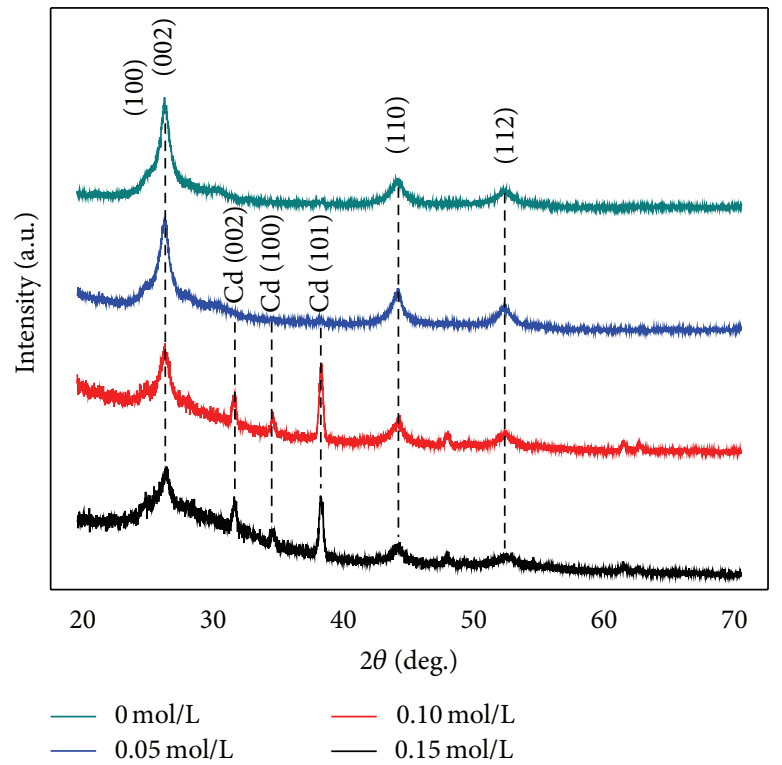

FIGURE 1: XRD patterns of CdS/Si-NPA with the buffer agent concentration of $0 \mathrm{~mol} \mathrm{~L}^{-1}, 0.05 \mathrm{~mol} \mathrm{~L}^{-1}, 0.10 \mathrm{~mol} \mathrm{~L}^{-1}$, and $0.15 \mathrm{~mol} \mathrm{~L}^{-1}$.

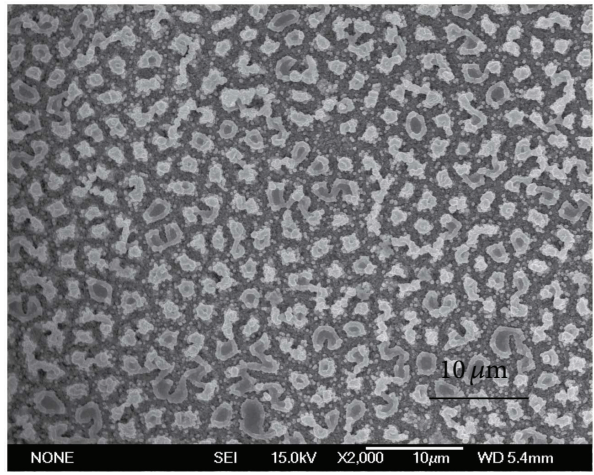

(a)

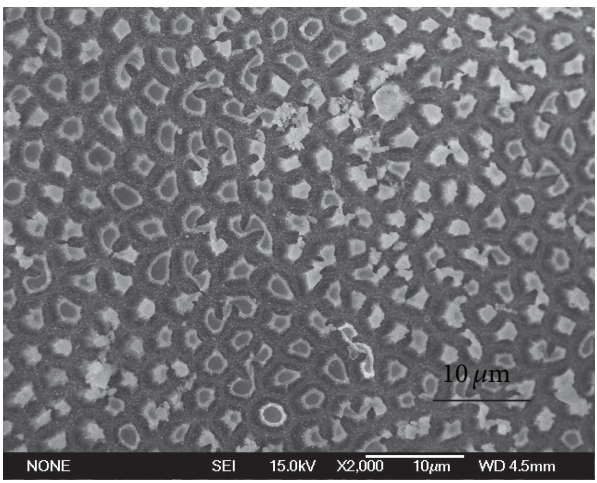

(c)

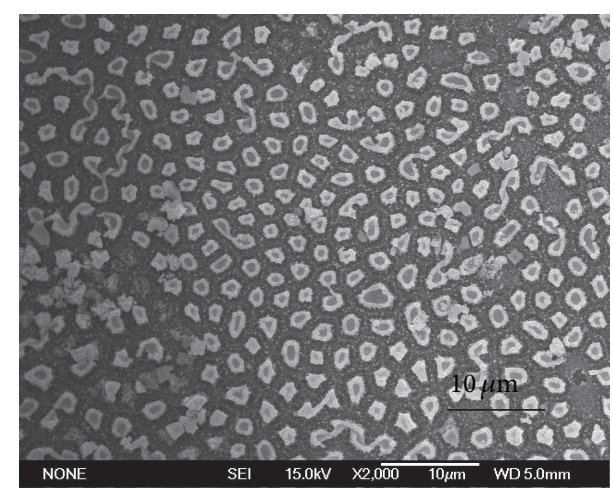

(b)

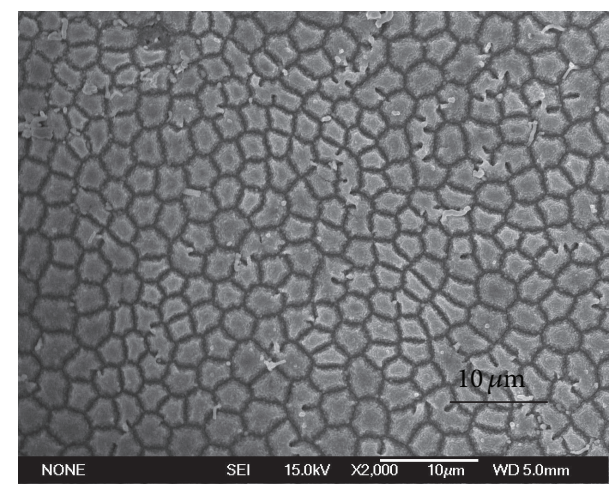

(d)

FIGURE 2: SEM images of CdS/Si-NPA, (a) $0 \mathrm{~mol} \mathrm{~L}^{-1}$, (b) $0.05 \mathrm{~mol} \mathrm{~L}^{-1}$, (c) $0.10 \mathrm{~mol} \mathrm{~L}^{-1}$, and (d) $0.15 \mathrm{~mol} \mathrm{~L}^{-1}$.

Here, $\alpha$ is the absorption coefficient, $B$ is the characteristic parameter independent of photon energy, $h v$ is the incident photon energy, $E_{g}$ is the optical band gap, and $n$ is a constant which depends on the nature of the transition between the valance band and conduction band, for $\operatorname{CdS} n=2$. The evolution of $(\alpha h \nu)^{2}$ versus $h v$ is displayed in Figure 3(b), and the obtained optical band gaps are $\sim 2.22 \mathrm{eV}(\sim 559 \mathrm{~nm}), \sim 2.37 \mathrm{eV}$ $(\sim 523 \mathrm{~nm}), \sim 2.39 \mathrm{eV}(\sim 519 \mathrm{~nm})$, and $\sim 2.46 \mathrm{eV}(\sim 504 \mathrm{~nm})$ for the buffer agent concentration of $0 \mathrm{~mol} \mathrm{~L}^{-1}, 0.05 \mathrm{~mol} \mathrm{~L}^{-1}$, $0.10 \mathrm{~mol} \mathrm{~L}^{-1}$, and $0.15 \mathrm{~mol} \mathrm{~L}^{-1}$, respectively.

In order to deeply understand the effect of buffer agent concentration for CdS/Si-NPA on the optical properties, the 


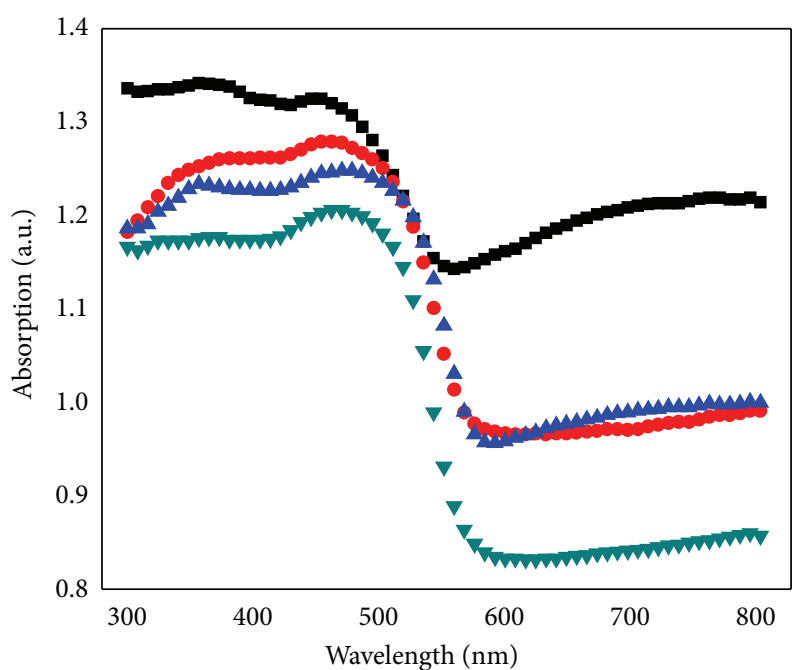

- $0.15 \mathrm{~mol} / \mathrm{L}$

- $0.10 \mathrm{~mol} / \mathrm{L}$

A $0.05 \mathrm{~mol} / \mathrm{L}$

$\checkmark 0 \mathrm{~mol} / \mathrm{L}$

(a)

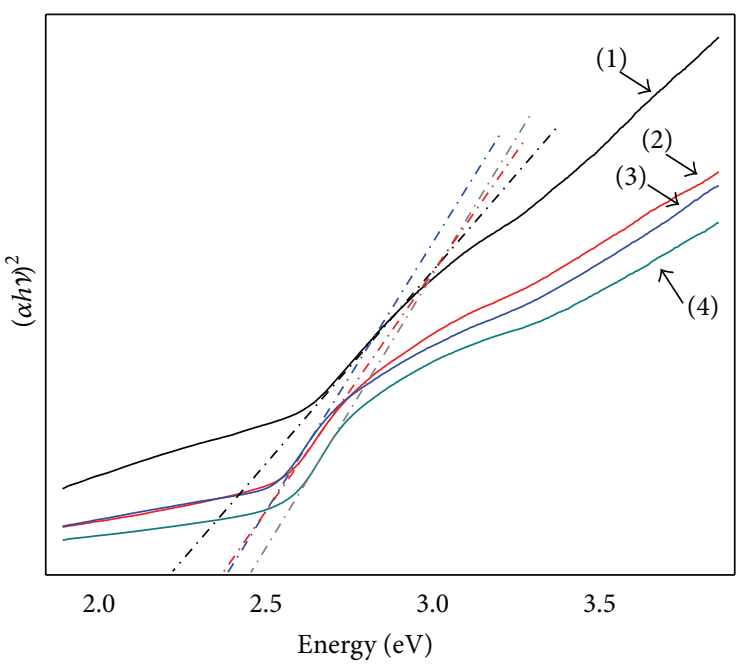

$\begin{array}{ll}\text { (1) } 0 \mathrm{~mol} / \mathrm{L} & \text { (3) } 0.10 \mathrm{~mol} / \mathrm{L}\end{array}$

(2) $0.05 \mathrm{~mol} / \mathrm{L}$

(4) $0.15 \mathrm{~mol} / \mathrm{L}$

(b)

FIgURE 3: (a) Absorption of CdS/Si-NPA, (b) the plots of $(\alpha h \nu)^{2}$ versus $h v$.

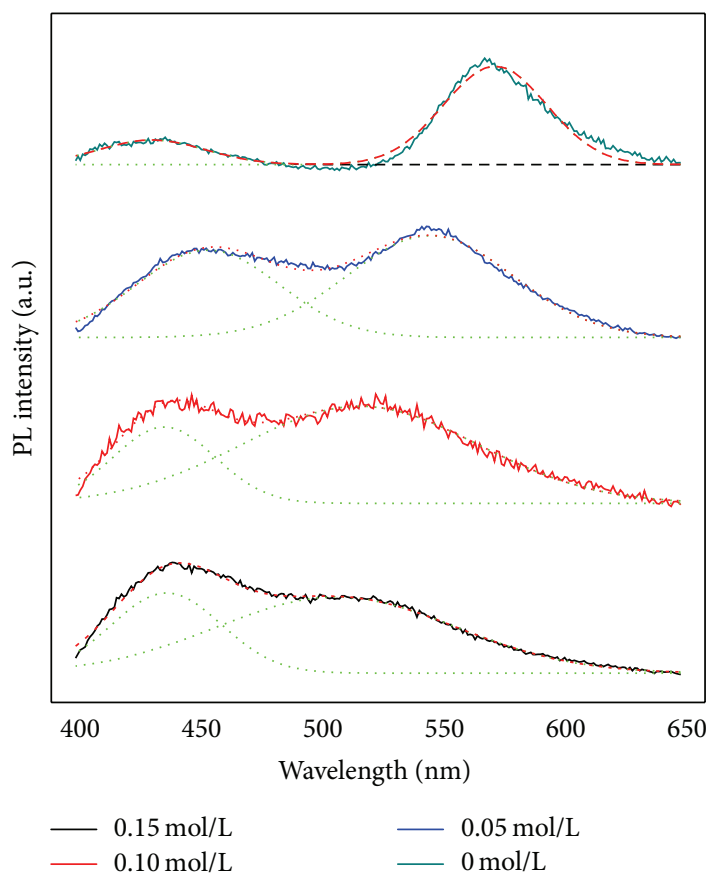

(a)

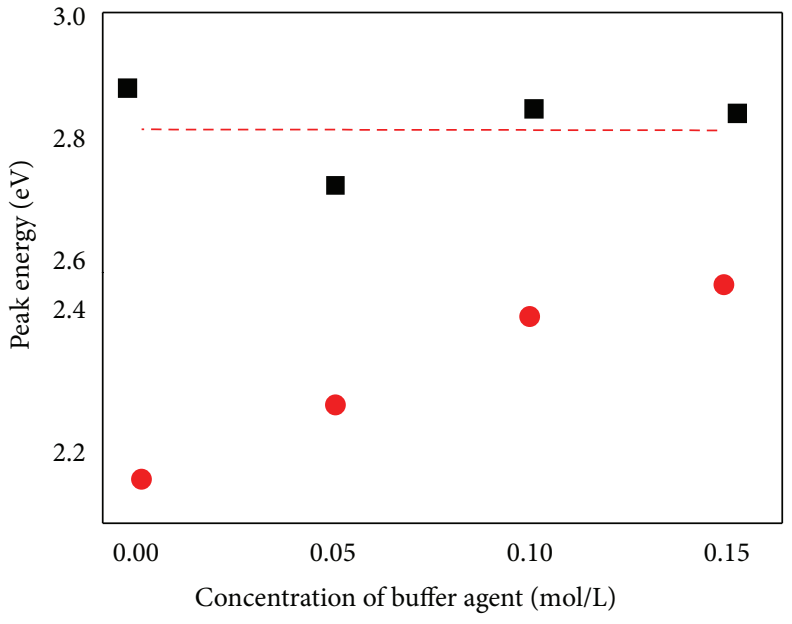

- Blue emission

- Green emission

(b)

room temperature photoluminescence with the different concentration is shown in Figure 4(a). The broad blue and green emission bands can be observed. With the increasing buffer agent concentration, the ratios of green versus blue emission intensity are $\sim 3.57, \sim 1.25, \sim 0.93$, and $\sim 0.69$, respectively. It can be seen from Figure 4(a) that the peaks of green emissions show blue shift. PL spectra can be decomposed into two peaks utilizing Gauss-Newton fitting method. The development of the blue and green energy with the increasing buffer agent concentration is shown in Figure 4(b). The blue emission energy is $\sim 2.87 \mathrm{eV}, \sim 2.73 \mathrm{eV}, \sim 2.84 \mathrm{eV}$, and $\sim 2.83 \mathrm{eV}$ for the agent buffering concentration of $0 \mathrm{~mol} \mathrm{~L}^{-1}, 0.05 \mathrm{~mol} \mathrm{~L}^{-1}$, $0.10 \mathrm{~mol} \mathrm{~L}^{-1}$, and $0.15 \mathrm{~mol} \mathrm{~L}^{-1}$, respectively. For the green emissions the peak energy is $\sim 2.16 \mathrm{eV}$ for $0 \mathrm{~mol} \mathrm{~L}^{-1}, \sim 2.27 \mathrm{eV}$ 
for $0.05 \mathrm{~mol} \mathrm{~L}^{-1}, \sim 2.40 \mathrm{eV}$ for $0.10 \mathrm{~mol} \mathrm{~L}^{-1}$, and $\sim 2.44 \mathrm{eV}$ for $0.15 \mathrm{~mol} \mathrm{~L}^{-1}$, respectively.

In the previous works, the blue emissions from $\mathrm{CdS} / \mathrm{Si}$ NPA can be ascribed to the luminescence of Si-NPA substrate $[9,20,21]$, which originates from the silicon oxide layer [22]. The evolution of blue emission peaks is illustrated in Figure 4(b) and observed to be irregular. Through analyzing the data, a linear fit can be obtained with the tiny slop of $\sim-0.01 \mathrm{meV}$ per $\mathrm{mol} \mathrm{L}^{-1}$, which indicates that the peak energy of blue emissions is hardly dependent on the buffer agent concentration. The average peak energy is $\sim 2.82 \mathrm{eV}$ $(\sim 440 \mathrm{~nm})$ which is consistent with the previous results [15]. The green emissions originate from the near band gap of CdS nanocrystals $[9,14,23]$. With the increasing buffer agent concentration, the peak energy of green emissions gradually increases. Namely, the green emissions show blue shift with the increasing buffer agent concentration. The variation of green emissions is consistent with the results from the absorption using Tauc's relation. According to the quantum size effect, the smaller the CdS nanocrystals, the wider the band gap. It is indicated that with the increasing buffer agent concentration the average size of CdS nanocrystals is gradually decreased, and the band gap can be tuned. Therefore the idea through varying the concentration of buffer agent is an optional approach to tune the band gap and size of CdS nanocrystals grown by CBD method.

\section{Conclusion}

In summary, we have prepared CdS/Si-NPA with the buffer agent concentration of $0 \mathrm{~mol} \mathrm{~L}^{-1}, 0.05 \mathrm{~mol} \mathrm{~L}^{-1}, 0.10 \mathrm{~mol} \mathrm{~L}^{-1}$, and $0.15 \mathrm{~mol} \mathrm{~L}^{-1}$, respectively, through the $\mathrm{CBD}$ method. In the XRD spectra of CdS/Si-NPA with the buffer agent, the diffraction peaks of hexagonal $\mathrm{CdS}$ and $\mathrm{Cd}$ can be observed due to the reduction of $\mathrm{Cd}^{2+}$ caused by the Si-NPA. With the increasing buffer agent concentration, the average size of CdS nanocrystals is decreased and the optical band gaps are increased. The blue emissions of CdS/Si-NPA originate from the Si-NPA and are independent of the buffer agent concentration; however, the green emissions show blue shift with the increasing buffer agent concentration.

\section{Conflict of Interests}

The authors declare that there is no conflict of interests regarding the publication of this paper.

\section{Acknowledgments}

This work was supported by the Research Project for Basic and Forefront Technology of Henan Province (132300410301 and 152300410173), the Key Research Project for Science and Technology of the Education Department of Henan Province (13B430181 and 15A140012), and the Science and Technology Project on Key Problems of Pingdingshan City (2013085 and 2014082).

\section{References}

[1] A. Veamatahau, B. Jiang, T. Seifert et al., "Origin of surface trap states in CdS quantum dots: relationship between size dependent photoluminescence and sulfur vacancy trap states," Physical Chemistry Chemical Physics, vol. 17, no. 4, pp. 28502858, 2015.

[2] A. Varghese, P. Ghosh, and S. Datta, "Cadmium vacancy minority defects as luminescence centers in size and strain dependent photoluminescence shifts in CdS nanotubes," The Journal of Physical Chemistry C, vol. 118, no. 37, pp. 21604-21613, 2014.

[3] M. L. Mastronardi, F. Maier-Flaig, D. Faulkner et al., "Sizedependent absolute quantum yields for size-separated colloidally-stable silicon nanocrystals," Nano Letters, vol. 12, no. 1, pp. 337-342, 2012.

[4] K.-Y. Lee, J.-R. Lim, H. Rho, Y.-J. Choi, K. J. Choi, and J.-G. Park, "Evolution of optical phonons in CdS nanowires, nanobelts, and nanosheets," Applied Physics Letters, vol. 91, no. 20, Article ID 201901, 2007.

[5] S. S. Warule, N. S. Chaudhari, R. T. Shisode, K. V. Desa, B. B. Kale, and M. A. More, "Decoration of CdS nanoparticles on 3D self-assembled $\mathrm{ZnO}$ nanorods: a single-step process with enhanced field emission behaviour," CrystEngComm, vol. 17, no. 1, pp. 140-148, 2015.

[6] Y. Li, L. Gao, Y.-L. Song et al., "CdS nanowires array on Cd foil: synthesis and optical properties," Materials Letters, vol. 139, pp. 126-129, 2015.

[7] Q. Wang, J. Li, Y. Bai et al., "Photochemical preparation of $\mathrm{Cd} / \mathrm{CdS}$ photocatalysts and their efficient photocatalytic hydrogen production under visible light irradiation," Green Chemistry, vol. 16, no. 5, pp. 2728-2735, 2014.

[8] M. S. Song and Y. Kim, "Growth of bimodal Sn-catalyzed CdS nanowires by using tin sulfide," Journal of Physical Chemistry C, vol. 118, no. 11, pp. 5988-5995, 2014.

[9] Y. L. Song, H. Y. Bian, Y. Li et al., "Synthesis, structures and optical properties of $\mathrm{CdS}: \mathrm{Cd} / \mathrm{Si}$ multi-interface nanoheterojunction," Journal of Alloys and Compounds, vol. 637, pp. 133136, 2015.

[10] J. Jie, W. Zhang, I. Bello, C.-S. Lee, and S.-T. Lee, "Onedimensional II-VI nanostructures: synthesis, properties and optoelectronic applications," Nano Today, vol. 5, no. 4, pp. 313336, 2010.

[11] H. Li, X. Wang, J. Xu et al., "One-dimensional CdS nanostructures: a promising candidate for optoelectronics," Advanced Materials, vol. 25, no. 22, pp. 3017-3037, 2013.

[12] J. I. Wong, N. Mishra, G. Xing et al., "Dual wavelength electroluminescence from CdSe/CdS tetrapods," ACS Nano, vol. 8, no. 3, pp. 2873-2879, 2014.

[13] Y. Li, X. B. Wang, Y. T. Tian, and X. J. Li, "Effect of interface incorporation of cadmium nanocrystallites on the photovoltaic performance of solar cells based on CdS/Si multi-interface nanoheterojunction," Physica E: Low-dimensional Systems and Nanostructures, vol. 64, pp. 45-50, 2014.

[14] Y. Li, S. Q. Yuan, and X. J. Li, "White light emission from CdS/Si nanoheterostructure array," Materials Letters, vol. 136, pp. 6770, 2014.

[15] Y. Li, X. B. Wang, Z. Q. Fan, and X. J. Li, “Temperaturedependent photoluminescence of silicon nanoporous pillar array," Chinese Physics Letters, vol. 31, no. 4, Article ID 047801, 2014. 
[16] J. Herrero, M. T. Gutiérrez, C. Guillén et al., "Photovoltaic windows by chemical bath deposition," Thin Solid Films, vol. 361, pp. 28-33, 2000.

[17] C. He, C. B. Han, Y. R. Xu, and X. J. Li. J. Appl, "Photovoltaic effect of CdS/Si nanoheterojunction array," Journal of Applied Physics, vol. 110, no. 9, Article ID 094316, 2011.

[18] F. Feng, G. Zhi, H. S. Jia, L. Cheng, Y. T. Tian, and X. J. Li, "SERS detection of low-concentration adenine by a patterned silver structure immersion plated on a silicon nanoporous pillar array," Nanotechnology, vol. 20, no. 29, Article ID 295501, 2009.

[19] S. Kumar, P. Sharma, and V. Sharma, "CdS nanofilms: synthesis and the role of annealing on structural and optical properties," Journal of Applied Physics, vol. 111, no. 4, Article ID 043519, 2012.

[20] H. J. Xu and X. J. Li, “Three-primary-color photoluminescence from $\mathrm{CdS} / \mathrm{Si}$ nanoheterostructure grown on silicon nanoporous pillar array," Applied Physics Letters, vol. 91, Article ID 201912, 2007.

[21] Y. Li, X.-B. Wang, J.-C. Zhao, and X.-J. Li, "Paths for the non-radiative recombination occurring in $\mathrm{CdS}: \mathrm{CdO} / \mathrm{Si}$ multiinterface nanoheterostructure array," Chinese Physics Letters, vol. 31, no. 7, Article ID 077802, 2014.

[22] G. G. Qin, H. Z. Song, B. R. Zhang, J. Lin, J. Q. Duan, and G. Q. Yao, "Experimental evidence for luminescence from silicon oxide layers in oxidized porous silicon," Physical Review B: Condensed Matter and Materials Physics, vol. 54, no. 4, pp. 2548-2555, 1996.

[23] A. E. Abken, D. P. Halliday, and K. Durose, "Photoluminescence study of polycrystalline photovoltaic CdS thin film layers grown by close-spaced sublimation and chemical bath deposition," Journal of Applied Physics, vol. 105, no. 6, Article ID 064515, 2009. 

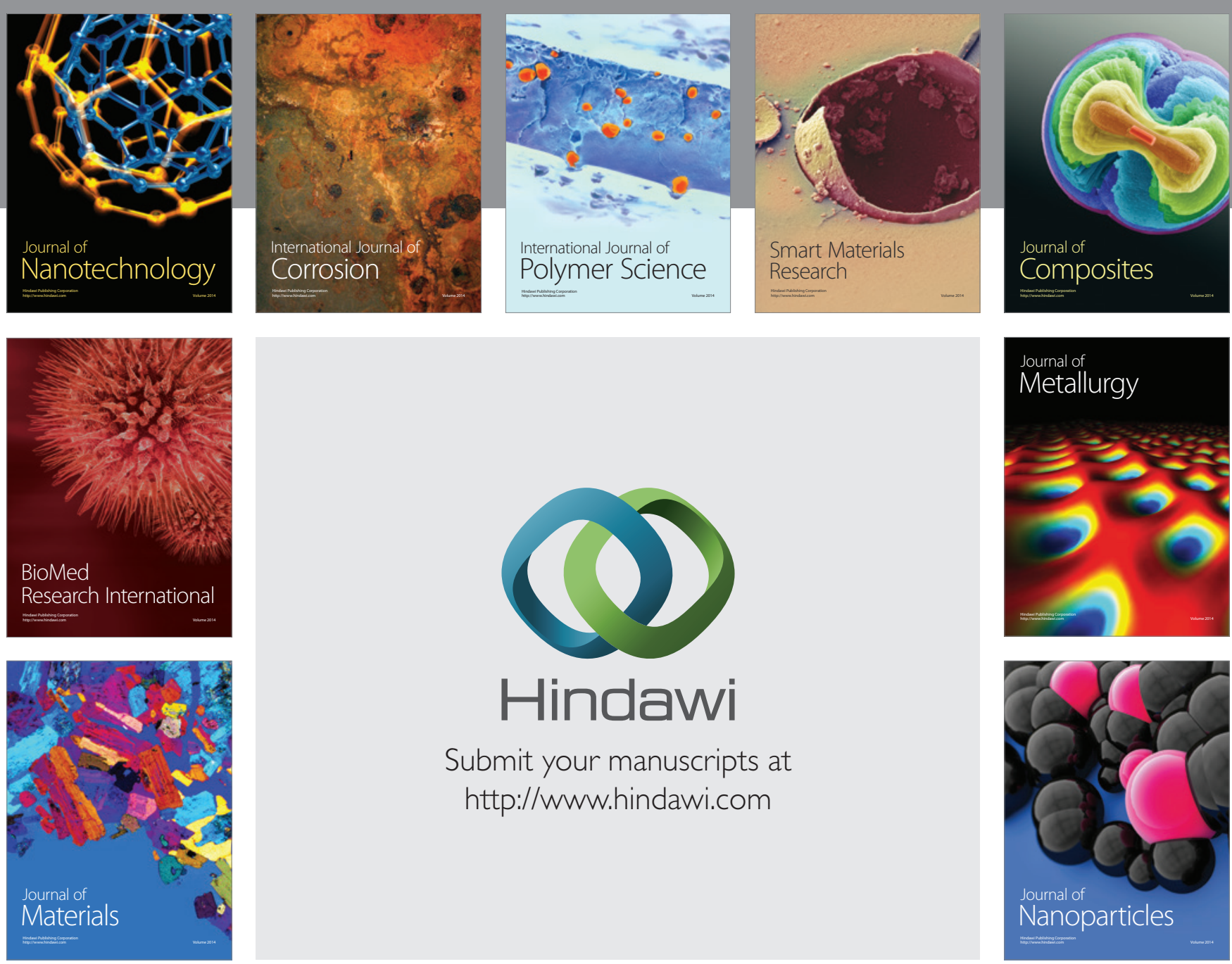

Submit your manuscripts at http://www.hindawi.com
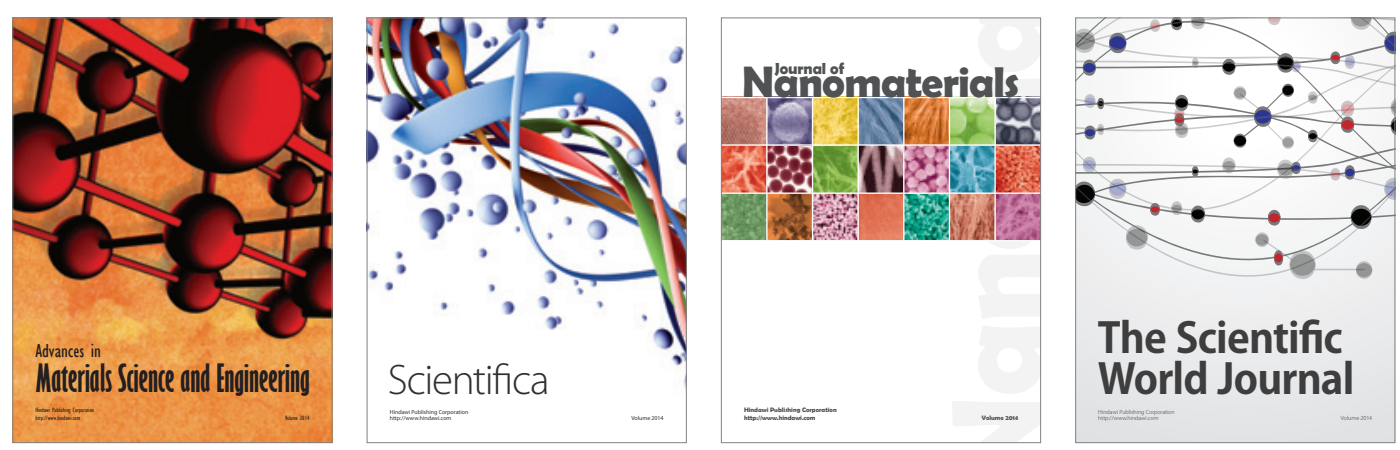

\section{The Scientific World Journal}
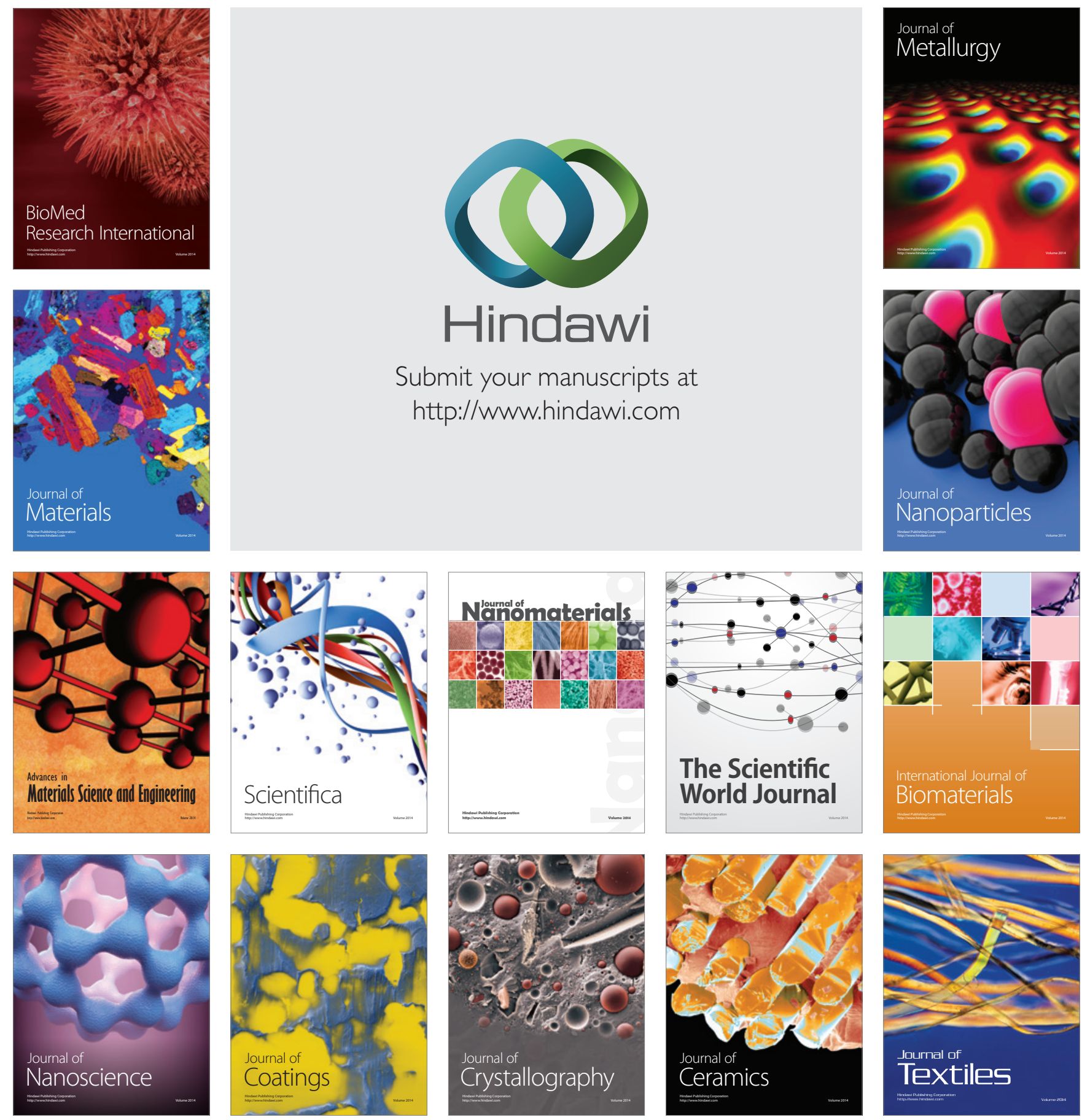